\title{
O PROCESSO EDUCACIONAL BRASILEIRO: DESAFIOS E FRUSTRAÇÕES
}

\section{ARTIGO ORIGINAL}

BASTOS, Manoel de Jesus ${ }^{1}$

BASTOS, Manoel de Jesus. O processo educacional brasileiro: Desafios e frustrações. Revista Científica Multidisciplinar Núcleo do Conhecimento. Ano 05, Ed. 06, Vol. 12, pp. 83-93. Junho de 2020. ISSN: 2448-0959, Link de acesso: https://www.nucleodoconhecimento.com.br/educacao/processo-educacional

\section{RESUMO}

O presente artigo faz menção ao andamento do atual processo educacional brasileiro, seus desafios e frustrações dentro das possibilidades dos segmentos que o operam. Seu principal objetivo é explicitar aos leitores a verdadeira realidade vivenciada pela sociedade brasileira, seus almejos, expectativas e decepções. Trata-se, portanto, de uma pesquisa de cunho bibliográfico com apego às concepções de alguns teóricos e de algumas fontes oficiais. Comumente, faz-se alusões sobre extraordinários projetos para a melhoria do processo educacional, no entanto, muitos deles não vingam, não saem do papel. Grande parte de suas metas deixam de ser cumpridas e terminam se esvaindo com o passar do tempo. A cidadania, produto de uma educação qualitativa está prevista na lei, no entanto, a sua execução vem sendo ignorada e o seu valor perdendo o sentido.

Palavras-chave: Educacionais, cidadania, sociedade, Políticas Públicas.

\footnotetext{
${ }^{1}$ Mestre em Ciências da Educação pela Absoulute Christian University, Pós-graduado em Supervisão Escolar pela Faculdade de Teologia Hokemãh - FATEH e Licenciado em Normal Superior pela Universidade Estadual do Piauí -UESPI.
} 


\section{INTRODUÇÃO}

A expectativa pela melhoria do sistema educacional brasileiro vem se intensificando, nos últimos anos, pela sociedade brasileira. A conclamação por políticas públicas, que venham atenuar os problemas educacionais, tem se tornado cada vez mais frequentes. Ideologias entrelaçam-se com olhares convergentes em busca da tão sonhada cidadania a que se refere a Constituição Federal no seu artigo 205:

A educação, direito de todos e dever do Estado e da família, será promovida e incentivada com a colaboração da sociedade, visando ao pleno desenvolvimento da pessoa, seu preparo para o exercício da cidadania e sua qualificação para o trabalho. (C. F. 1988, art. 205. p. 63)

Apesar do surgimento de algumas mudanças, positivamente, visíveis, como os avanços tecnológicos, o aperfeiçoamento profissional e o aumento da oferta de escolaridade, em todos os seus níveis, dentre outros, ainda é notória a diversidade de desafios que aguardam superação na área educacional. Isso se deve à ausência do cumprimento das leis educacionais propostas pelas políticas públicas, pelos desvios de recursos destinados que se desnorteiam por outros caminhos, deixando, é claro, de chegar ao seu público alvo.

Ademais, a falta de cumprimento das diretrizes criadas nas políticas educacionais tem sinalizado o enfraquecimento no processo educacional da educação básica, gerando, como consequências, o mascaramento social e o surgimento do analfabetismo funcional. É notório que elas vêm, ao longo dos anos, demonstrando uma certa vulnerabilidade dentro do seu contexto, deixando de oferecer a essência de suas propostas veiculadas às leis educacionais.

De modo que há uma necessidade muito grande de intensificação nessas políticas sociais para que possam proporcionar melhores resultados na educação brasileira. As propostas desenvolvidas nas leis educacionais, precisam estar em consonância com as necessidades vigentes do seu público alvo, uma vez que os perfis dos cidadãos vêm sofrendo mutações no decorrer dos anos. 
Acredita-se que os índices de analfabetismo e de baixo rendimento escolar dos alunos das escolas públicas brasileiras, possam ser atenuados a partir do momento em que a educação deixar de ser "um faz de conta" e passe a ser levada a sério pelo Estado e pela sociedade. Logo, as políticas educacionais devem ser criadas com o intuito de qualificar o indivíduo para o exercício da cidadania e do trabalho, da consciência de suas obrigações e dos seus direitos para servir melhor a sociedade na qual encontrase inserido. Se o indivíduo é modificado pelo ambiente social, torna-se necessário que se desenvolva ações de cunho resgatativo de uma sociedade pacífica e igualitária.

Nos últimos anos as políticas educacionais não têm demonstrado nenhuma alternativa de superação dos desafios encontrados pela sociedade. A cidadania deixou de ser prioridade e os seus valores escassearam-se. A realidade social em que se vive atualmente está sendo diferente a cada ano, pois as diversidades estão sendo fragilizadas a cada instante. Muitos jovens estão perdendo sua identidade e vê-se que a educação não está sendo capaz de mudar esse perfil de sociedade.

Os programas educacionais oferecidos pelo sistema, precisam ser fortalecidos para que possam realizar, com eficiência, suas propostas com embasamento nas necessidades da sociedade. $O$ desaceleramento ou a inércia do sistema contribuirá com o ciclo da marginalização, principalmente, da juventude brasileira. De acordo com Demo (1994), "algumas políticas sociais correm o risco intrínseco de ser estratagema de controle social e desmobilização dos "desiguais," segundo a lógica do poder." Dessa forma, cria-se empecilhos desnorteadores da verdadeira cidadania.

Nossas escolas estão precisando de políticas preventivas para o enfrentamento aos robustos desafios, o resgate dos valores éticos e a retomada da verdadeira cidadania. As políticas sociais, em todos os níveis, não têm demonstrado nenhuma perspectiva para o melhoramento da formação cidadã, tampouco por uma política que apresente diretrizes para a atenuação dos seus problemas. Diante de tal situação, o povo brasileiro apresenta um ceticismo considerável, em relação a construção da cidadania prevista na Constituição Federal. 
Pode-se ter uma concepção da importância da formação do indivíduo no Ensino Fundamental, tendo como essência, o domínio da leitura, da escrita e do cálculo para o prosseguimento, sem tropeços, da caminhada educacional, tendo em vista, ser essa a base de uma desenvoltura escolar almejada pela sociedade. O desenvolvimento do indivíduo no processo educacional vai depender de uma boa preparação nas primeiras séries, assegurando-lhe sucesso ininterrupto ao longo do processo.

\section{POLÍTICAS PÚBLICAS NA EDUCAÇÃO E O BAIXO RENDIMENTO DOS ALUNOS}

O que se tem percebido, hodiernamente, é um sistema educacional com grande fomentação por índices numerológicos que possam favorecer a aparição do país no topo das estatísticas mundial. A qualidade da educação, o suprimento das necessidades essenciais dos alunos, a ampliação dos espaços escolares e a valorização dos profissionais, entre outras, não fazem parte de suas diretrizes. Neste caso, cria-se programas de excelência, mas, com visões camufladas ao desenvolvimento educativo, obstruindo a formação emancipatória e satisfazendo aos interesses, meramente, capitalistas.

O baixo rendimento dos alunos no Ensino Fundamental é o resultado de uma série de fatores, mas o que normalmente se justifica é apenas a deficiência ou a incapacidade dos alunos. No entanto, segundo Guerra (2001), incapacidades de aprendizagem não devem ser confundidas com dificuldades.

Sendo assim, cabe a escola diagnosticar o estado geral do aluno, desde o contexto familiar (nascimento ou morte de pessoa da família, separação dos pais, desemprego ou doença, entre outros), levando em consideração as concepções de Roman e Steyer (2001), quando afirmam que os conflitos emocionais podem interferir no rendimento do aluno.

A escola jamais deverá se esquivar de sua tarefa de mediadora, fortalecendo a luta estudantil, através da motivação e da construção da parceria entre 
escola/família/comunidade. A transformação social só se efetivará mediante a criação de diretrizes que venham atender os requisitos exigidos pela coletividade.

O sistema educacional brasileiro pode até demonstrar preocupações com o andamento do ensino-aprendizagem, sobretudo com o aprendizado eficiente, porém continua elaborando ou reelaborando programas sociais isentos da parceria da sociedade, principalmente dos profissionais da área que, vivenciam os reais problemas e poderiam apontar vertentes atenuadoras para esse mal que cresce desordenadamente. Não basta criar programas, é preciso que se reflita, se invista melhor e eficazmente, e fiscalize os recursos destinados a esses projetos.

Obviamente, o sistema educacional vem proporcionando a ampliação de acesso ao ensino público, com a criação de novos programas que tem como objetivo atenuar o analfabetismo brasileiro e qualificar indivíduos para o mercado de trabalho. São programas que trazem no seu bojo muitas diretrizes que, uma vez consolidadas, poderiam mudar, positivamente, a situação crítica a que se vivencia atualmente. No entanto, devido à falta de cumprimento, esses programas perdem o fôlego no decorrer do percurso, deixando de serem enérgicos e tornando-se mera utopia.

A escola é a principal responsável pela formação cidadã, jamais deixando de exercer o seu papel de mediadora, mesmo havendo a alienação produzida pelo sistema. Cabe-Ihe, portanto, desenvolver ações que possam sensibilizar os alunos da imprescimbilidade da formação para a vida e para o desenvolvimento posterior de uma Pátria que os aguarda.

Diante das incessantes dificuldades enfrentadas pelas escolas, alarga-se mais ainda a necessidade de outros profissionais, para que ombreados aos professores possam amenizar os problemas que vem obstruindo o desenvolvimento educacional. O aceleramento aleatório no currículo escolar certamente não produzirá o que se almeja. É preciso que que se desenvolva um olhar reflexivo e avaliador sobre o processo, para se chegar a um resultado satisfatório. 


\subsection{BAIXO RENDIMENTO: O VILÃO NO PROCESSO EDUCACIONAL}

O segundo semestre do ano letivo é o período em que se observa as maiores preocupações por parte dos alunos que não conseguiram notas suficientes e passam a correr o risco de uma possível retenção. Obviamente, poderia evitar-se tal constrangimento, se houvesse a valorização do processo ensino-aprendizagem, continuamente. Chegar ao segundo semestre sem déficit disciplinar, vai depender do esforço contínuo e perseverante.

Acredita-se na superação do processo educacional a partir do momento em que houver um acompanhamento ininterrupto pela comunidade escolar, diagnosticando as supostas causas empecilhadoras, discutindo-as com seus parceiros e propondo sinalizadores que venham atenuá-las. Nessas circunstâncias, escola, família e sociedade precisam somar esforços enérgicos para o cumprimento das diretrizes educacionais e a contenção dos males obstruidores do processo.

O baixo rendimento escolar é um fenômeno preocupante que vem se agravando dia após dia, porém nenhum segmento quer assumir a culpabilidade. Esquiva-se do problema e aponta-se a desestrutura da família, o desinteresse do aluno, as condições socioeconômicas etc. De acordo com Perrenoud (2000),

É a própria organização escolar do trabalho pedagógico que gera o insucesso escolar, isto significa que o aluno encontra na escola um ambiente bem diferente do que esperava, por este motivo, em algumas realidades, acaba sendo reprovado ou obtendo baixo rendimento escolar (PERRENOUD, 2000, p. 02).

Preocupado com os resultados que apresentam-se aquém das expectativas, o Brasil vem tentando superar as metas oferecidas pelo Ministério da Educação - MEC, obtendo êxito, de acordo com o Índice de Desenvolvimento da Educação Básica IDEB/2017, apenas nos anos iniciais do Ensino Fundamental com o resultado de 5,5 além da meta projetada, 5,2 , deixando de superar as demais projetadas para os anos 
finais do Ensino Fundamental, com a obtenção de 4,4 ao invés de 4,7 e no Ensino Médio, 3,5 em vez de 4,4.

IDEB - Resultados e Metas

IDEB 2005, 2007, 2009, 2011, 2013, 2015, 2017 e Projeções para o BRASIL

\section{Anos Iniciais do Ensino Fundamental}

\begin{tabular}{|c|c|c|c|c|c|c|c|c|c|c|c|c|c|c|c|}
\hline & \multicolumn{7}{|c|}{ IDEB Observado } & \multicolumn{8}{|c|}{ Metas } \\
\hline & 2005 & 2007 & 2009 & 2011 & 2013 & 2015 & 2017 & 2007 & 2009 & 2011 & 2013 & 2015 & 2017 & 2019 & 2021 \\
\hline Total & 3.8 & 4.2 & 4.6 & 5.0 & 5.2 & 5.5 & 5.8 & 3.9 & 4.2 & 4.6 & 4.9 & 5.2 & 5.5 & 5.7 & 6.0 \\
\hline \multicolumn{16}{|c|}{ Dependência Administrativa } \\
\hline Estadual & 3.9 & 4.3 & 4.9 & 5.1 & 5.4 & 5.8 & 6.0 & 4.0 & 4.3 & 4.7 & 5.0 & 5.3 & 5.6 & 5.9 & 6.1 \\
\hline Municipal & 3.4 & 4.0 & 4.4 & 4.7 & 4.9 & 5.3 & 5.6 & 3.5 & 3.8 & 4.2 & 4.5 & 4.8 & 5.1 & 5.4 & 5.7 \\
\hline Privada & 5.9 & 6.0 & 6.4 & 6.5 & 6.7 & 6.8 & 7.1 & 6.0 & 6.3 & 6.6 & 6.8 & 7.0 & 7.2 & 7.4 & 7.5 \\
\hline Pública & 3.6 & 4.0 & 4.4 & 4.7 & 4.9 & 5.3 & 5.5 & 3.6 & 4.0 & 4.4 & 4.7 & 5.0 & 5.2 & 5.5 & 5.8 \\
\hline
\end{tabular}

Fonte: IDEB

\section{Anos Finais do Ensino Fundamental}

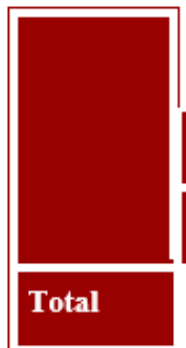

IDEB Observado
\begin{tabular}{|l|l|l|l|l|l|l|l|l|l|l|l|l|l|l|}
\hline 2005 & 2007 & 2009 & 2011 & 2013 & 2015 & 2017 & 2007 & 2009 & 2011 & 2013 & 2015 & 2017 & 2019 & 2021 \\
\hline
\end{tabular}

Dependência Administrativa

\begin{tabular}{|c|c|c|c|c|c|c|c|c|c|c|c|c|c|c|c|}
\hline Estadual & 3.3 & 3.6 & 3.8 & 3.9 & 4.0 & 4.2 & 4.5 & 3.3 & 3.5 & 3.8 & 4.2 & 4.5 & 4.8 & 5.1 & 5.3 \\
\hline Municipal & 3.1 & 3.4 & 3.6 & 3.8 & 3.8 & 4.1 & 4.3 & 3.1 & 3.3 & 3.5 & 3.9 & 4.3 & 4.6 & 4.9 & 5.1 \\
\hline Privada & 5.8 & 5.8 & 5.9 & 6.0 & 5.9 & 6.1 & 6.4 & 5.8 & 6.0 & 6.2 & 6.5 & 6.8 & 7.0 & 7.1 & 7.3 \\
\hline Pública & 3.2 & 3.5 & 3.7 & 3.9 & 4.0 & 4.2 & 4.4 & 3.3 & 3.4 & 3.7 & 4.1 & 4.5 & 4.7 & 5.0 & 5.2 \\
\hline
\end{tabular}

Fonte: IDEB

$\mathrm{RC}: 53160$

Disponível em: https://www.nucleodoconhecimento.com.br/educacao/processo-educacional 
Diante dos resultados acima demonstrados, ferve a preocupação de superação dessas perdas de aprendizagem e a fomentação pelo cumprimento dos artigos: 32 , inciso I e 35, inciso II da LDB:

Art. 32. O ensino fundamental obrigatório de nove anos, gratuito na escola pública, iniciando-se aos seis anos de idade, terá por objetivo a formação básica do cidadão, mediante:

I - O desenvolvimento da capacidade de aprender, tendo como meios básicos o pleno domínio da leitura, da escrita e do cálculo.

Art. 35. O ensino médio, etapa final da educação básica, com duração mínima de três anos, terá como finalidade:

II - A preparação básica para o trabalho e a cidadania do educando, para continuar, de modo a ser capaz de se adaptar com flexibilidade as novas condições de ocupação ou aperfeiçoamento posteriores.

Observa-se, portanto, que as garantias previstas nas leis educacionais não estão sendo cumpridas, tampouco consideradas como norteadoras do ensinoaprendizagem. É preciso que cada segmento compreenda a importância da escolarização, envolvendo-se no processo, considerando-o como algo essencial à formação da cidadania e o equilíbrio social. A socialização de um povo se dá através de uma educação qualitativa, cujos objetivos estejam voltados para o desenvolvimento afetivo, intelecto e sociocultural dos indivíduos que o compõem.

Ademais, por ser a educação a base para uma sociedade pautada na cidadania, requer uma profunda reavaliação com a implementação de políticas públicas que favoreçam a ascensão social das pessoas, diminuindo as diferenças e a alienação cultural. Mediante a essa concepção, percebe-se a imprescimbilidade de acompanhamento do processo, ininterruptamente, avaliando-o e buscando alternativas para o seu dimensionamento, de modo geral. 


\subsection{A TAREFA COLETIVA SOBRE O FRACASSO ESCOLAR}

O sucesso ou o insucesso do desenvolvimento educacional não se restringe apenas aos professores e aos alunos, mas abrangente à comunidade escolar, cabendo-a abraçar a causa, valorizando e proporcionando programas inclusivos às crianças e aos jovens que se encontram fora da escola. Esses segmentos necessitam de um olhar mais autêntico e afetivo, instrumentalizando, valorizando e dando importância à verdadeira ferramenta construtora da cidadania e do status social: o estudo.

O que se tem observado, nos últimos anos, são práticas ineficazes para o combate às dificuldades e ao mau funcionamento da aprendizagem em grande parte das escolas públicas brasileiras. As parcerias entre os segmentos nas instituições educacionais, estão precisando serem reajustadas com almejos aos mesmos objetivos e as mesmas perspectivas. É com esse ombreamento e com essa somatória de esforços, de todos os segmentos envolvidos, no processo educacional que os bons resultados poderão aparecer.

Apesar da criação das muitas políticas públicas voltadas à educação, o índice do baixo rendimento no Ensino Fundamental ainda é considerado exorbitante pois, vem gerando, como consequências, a vasão e a retidão escolar. Dessa forma, surge os atrasos nos estudos ou a queima da faixa etária propícia, onde grande parte desses alunos tentam a superação através de cursos suplementares. Para Weiss (1997),

A insuficiência na aprendizagem escolar pode estar ligada à essência de estrutura cognoscitiva, que permite a organização dos estímulos e favorece a aquisição dos conhecimentos. Todavia, a dificuldade em aprender pode estar relacionada a determinantes sociais da escola, do olhar do professor e do próprio aluno, ou seja, ligada a fatores internos (cognitivos/emocionais) e externos (culturais/sociais/políticos. (WEISS, 1997, p. 16)

A ineficiência do desempenho escolar, sobretudo no Ensino Fundamental tem sido um agravante incomodativo e que exige medidas emergenciais para a sua contenção. 
Para tanto, faz-se necessário que escola/família unifiquem suas concepções para a celebração da educação prevista para a cidadania. A essência de valores educacionais precisa ser resgatada com a certeza de que somente a educação tem o poder de transformação social, possibilitando a atenuação dos aspectos negativos e gerando o senso crítico, político e cultural.

Tendo em vista a série de fatores responsáveis pelo fracasso escolar, há a necessidade de reflexões e esforços capazes de reparar o caos na educação brasileira. Aqui destaca-se, mais uma vez, a importância das leis pedagógicas, que não são cumpridas como deveria, pois segundo elas:

a) Os projetos políticos-pedagógicos das escolas e os regimentos escolares deverão, pois, obrigatoriamente, disciplinar os tempos e espaços de recuperação, de preferência paralelos ao período letivo, tal como determina a LDB, e prever a possibilidade de aceleração de estudos para os alunos com atraso escolar. Há ainda que assegurar tempos e espaços de reposição dos conteúdos curriculares ao longo do ano letivo aos alunos com frequência insuficiente, evitando, sempre que possível, a retenção por faltas. (DCNEB, parag. 5ำ p. 123)

b) Os estabelecimentos de ensino, respeitadas as normas comuns e as do seu sistema de ensino, terão a incumbência de:

V - Prover meios para a recuperação dos alunos de menor rendimento. (Art. 12 -LDB)

c) Os docentes incumbir-se-ão de:

IV - Estabelecer estratégias de recuperação para os alunos de menor rendimento. (Art. 13 - LDB)

d) São direitos do estudante, além do previsto nas legislações vigentes:

V - Ser orientado em suas dificuldades; 
$\mathrm{VI}$ - Ter assegurado o direito de recuperar o seu baixo rendimento escolar; (Art. 65 - Reg. das Unid. Esc. Est. Bahia)

e) Manter e ampliar programas e ações de correção de fluxo do ensino fundamental, por meio do acompanhamento individualizado do (a) aluno (a) com rendimento escolar defasado e pela adoção de práticas como aulas de reforço no turno complementar, estudos de recuperação e progressão parcial, de forma a reposicioná-lo, no ciclo escolar de maneira compatível com sua idade. (PNE, Meta 3, Estratégia 35)

Notadamente, por ser um país capitalista e por obedecer a interesses de organismos internacionais, o nosso país vem deixando de cumprir com as suas políticas educacionais. Diante dessa realidade explícita que se vivencia observa-se que, o que realmente existe, é a padronização de modelos internacionais que, muitas vezes, divergem com a realidade e a necessidade do povo brasileiro. Por essas vertentes, a educação brasileira jamais prosperará e o país jamais atingirá suas metas propostas em seus programas educacionais, perdurando assim o mascaramento, a pobreza e o comodismo.

\section{ESTRUTURA SOCIAL E ASPECTOS CULTURAIS}

Conforme previsão nas leis educacionais, defende-se que o espaço físico escolar seja um lócus que propicie conforto e comodidade aos alunos e aos profissionais. No entanto, esse padrão de exigência não vem sendo cumprido pois, segundo levantamento realizado pelo movimento "Todos pela Educação" (2016), com base no Censo 2015 , apenas $4,5 \%$ das escolas públicas brasileiras dispõe dos itens de infraestrutura previstos no PNE, sendo mais críticos no Ensino Fundamental com $4,8 \%$ de itens positivos.

Logicamente, o desenvolvimento educacional se dá mediante às condições necessárias exigidas pelo aprendizado desde o acesso aos recursos elétricos, hídricos, espaços esportivos, laboratórios, acessibilidade, ventilação, além de outros. Todavia, a ausência de estruturação adequada nos centros educacionais, implica 
numa educação retrógrada e despida dos avanços previstos nas leis e esperados pela sociedade.

O resquício de uma educação administrada por um sistema que não leva em consideração todos os itens necessários ao seu bom funcionamento é de uma formação fragilizada e mal sucedida. O baixo rendimento dos nossos alunos, sobretudo, na etapa inicial da educação básica retrata a falta de compromisso e a ausência de esforços coletivos que resultem em uma educação qualitativa. Se a educação é considerada a verdadeira instrumentalizadora que norteia o progresso de uma nação, está na hora de atenuar nos discursos e avançar na prática.

Percebe-se da necessidade de enfrentamento à crise na educação básica com a valorização das parcerias entre escola/família/sociedade com o intuito de subsidiar uma educação que facilite o exercício da cidadania e proporcione às integrações dos nossos jovens no seio social. É preciso que se invista mais na base educacional com programas que proporcionem aos nossos jovens o gosto e a fomentação pela leitura, pela escrita e pelo cálculo, considerando a sua imprescimbiidade para os avanços em todos os setores socioculturais.

Acredita-se na impossibilidade de se fazer uma educação qualitativa sem a participação da sociedade. A comunidade escolar, por sua vez, deve analisar o andamento do processo, valorizando os pontos positivos e pontuando os que precisam ser melhorados. É com essa concepção que os problemas se tendem a ser atenuados e a qualidade do ensino-aprendizagem recuperada.

Fazer menção a estrutura social de um indivíduo dentro de um sistema sem considerar a essência da educação para o seu desenvolvimento não faz sentido. Vale a pena ressaltar que, sendo a família o primeiro grupo social que o indivíduo participa, cabeIhe o papel exclusivo de educar. É extremamente correta a afirmação do ex-presidente do Uruguai, Pepe Mujica, quando diz: "Não esperemos que os professores consertem as falhas na educação dos filhos..." A família é, sabidamente, o meio mais influenciador da ordem moral, social e afetiva. Acredita-se que grande parte da 
desaceleração no desempenho escolar pode estar relacionado ao nível socioeconômico e às características familiares.

\section{CONSIDERAÇÕES FINAIS}

Diante da situação que se vivencia, atualmente, surgem alguns questionamentos: $\mathrm{O}$ que está faltando para que o processo educacional brasileiro possa, realmente, atender às necessidades essenciais da sociedade? A nossa sociedade está se comportando em conformidade com o que prediz a Constituição Brasileira?

No entanto, há uma necessidade muito grande de políticas públicas direcionadas ao enfrentamento da crise na educação básica, viabilizando parcerias entre escola/família/comunidade com o intuito de subsidiar uma educação que proporcione o exercício da cidadania e a integração dos nossos jovens numa sociedade estabilizada. É preciso que se injete maiores investimentos na base educacional, com a oferta de programas que proporcionem aos nossos jovens o gosto e a fomentação pela leitura, pela escrita e pelo cálculo, considerando a sua importância para os avanços em todos os setores socioculturais.

Ademais, as normativas educacionais estão precisando de compromissos mais enérgicos para a sua efetivação. Elaborou-se leis educacionais com excelentes metas e invejáveis objetivos, mas ignora-se os seus cumprimentos na íntegra. É preciso que se faça algumas reflexões a respeito do andamento do processo educacional, nos últimos anos, para posteriores ações inovadoras com o intuito de corrigir as falhas que o desnorteiam.

A educação brasileira precisa sair do "faz de conta" e ser levada a sério por todos os segmentos que a conduz. Não basta excelentes teorias se a prática é ignorada ou trabalhada de forma deficitária. A sociedade conclama por políticas públicas que possibilitem uma educação de acordo com a prevista nas leis educacionais e em consonância às suas necessidades. Logo, as políticas públicas devem ser elaboradas com o objetivo preparar o indivíduo para exercer a sua cidadania e o seu profissionalismo, na sociedade da qual faz parte. 
Em síntese, a sociedade brasileira precisa conduzir em suas próprias veias a cultura da valorização da educação, tendo-a como principal propiciadora da transformação social. Contudo, ou se valoriza a educação para a estabilização social de um povo ou se assistirá, de camarote, os altos índices de analfabetos funcionais e as exorbitantes taxas de crescimento da pobreza e das desigualdades sociais.

\section{REFERÊNCIAS}

BRASIL, Constituição 1988. Constituição da República Federativa do Brasil. Senado, 1988.

BRASIL, Diretrizes Curriculares Nacionais da Educação Básica - DCNEB Ministério da Educação. Secretaria de Educação Básica. Diretoria de Currículos e Educação Integral. Brasília: MEC, SEB, DICEI, 2013.

BRASIL, Índice de Desenvolvimento da Educação Básica - IDEB. Consulta ao Índice Nacional sobre metas e resultados alcançados. Ano 2017.

BRASIL, Ministério da Educação e Desporto. Lei de Diretrizes e Bases da Educação Nacional - LDBEN/Lei no 9.394/96.

BRASIL, Plano Nacional de Educação - PNE, Lei no 13.005, de 25 de junho de 2014.

DEMO, P. Política Social, Educação e Cidadania. Campinas: Papirus, 1994.

GUERRA, L. B. A criança com dificuldades de aprendizagem. Rio de Janeiro: Enelivros, 2002.

PERRENOUD, P. Pedagogia diferenciada: das intenções a ação. Porto Alegre: Artmed. 2000.

Regimento das Unidades Escolares do Estado da Bahia. DOE, 17 de julho de 2001.

ROMAN, E, D. e STEYER, V. E. Acriança de $\mathbf{0}$ a $\mathbf{6}$ anos e a educação infantil: Um retrato multifacetado. Canoas: Ed. ULBRA, 2001. 
WEISS, L. M. L.L. Psicopedagogia Clínica: uma visão diagnóstica dos problemas de aprendizagem escolar. Rio de Janeiro: D. P. \& A. 1997.

Enviado: Outubro, 2019.

Aprovado: Junho, 2020. 